Revista Destaques Acadêmicos, Lajeado, v. 12, n. 1, 2020. ISSN 2176-3070

DOI: http://dx.doi.org/10.22410/issn.2176-3070.v12i1a2020.2502

http://www.univates.br/revistas

\title{
PRÁTICAS AMBIENTAIS NO PODER JUDICIÁRIO: UMA ANÁLISE DA GESTÃO DO FÓRUM NA COMARCA DE JUARA-MT
}

\author{
Luana Maritza de Brito' ${ }^{1}$ Vivieni Lara Machado², \\ Luciano Aparecido de Oliveira ${ }^{3}$, Agilson Poquiviqui ${ }^{4}$
}

Resumo: O presente estudo teve como objetivo compreender quais as práticas da gestão ambiental adotadas pelo Tribunal de Justiça do Estado de Mato Grosso aplicadas no Fórum da comarca de Juara-MT. A adoção de práticas ambientais está vinculada à utilização consciente dos recursos disponíveis, visto ser um procedimento de apoio às políticas ambientais. A capacitação e a conscientização dos servidores para a correta utilização e destinação dos resíduos sólidos contribui para a preservação e o monitoramento do meio ambiente. $\mathrm{O}$ estudo foi de abordagem qualitativa; para obtenção dos dados realizou-se uma entrevista com a gestora da organização e aplicação de questionário fechado aos servidores. Os resultados da pesquisa indicaram que há a necessidade de maior de conscientização ambiental por parte dos servidores, visto serem agentes ativos no processo.

Palavras-chave: Práticas ambientais. Responsabilidade social. Servidores.

1 Bacharel em administração, pela Universidade do Estado de Mato Grosso - Unemat. E-mail: brittol135@gmail.com

2 Bacharel em administração, Mestre em Ambiente e Sistema de Produção Agrícola, Especialização em Gestão Empresarial MBA - Fundação Getúlio Vargas. Unemat. E-mail: vivienimachado@gmail.com

3 Bacharel em administração, Mestre em Ambiente e Desenvolvimento, e doutorando pela Univates. Unemat. E-mail: lucianoolivetto@hotmail.com

4 Bacharel em ciências contábeis, Mestre em Administração, Doutor em sociologia UfsCar, professor da Universidade do Estado de Mato Grosso - Unemat. E-mail: a.poquiviqui@ unemat.br 


\section{INTRODUÇÃO}

Em decorrência das grandes discussões acerca da problemática ambiental, organizações exploram novas posturas, tendo em vista um processo de renovação contínua de novos valores. Acresce-se que na década de 70, a questão ambiental foi um dos assuntos mais debatidos, pois o modelo econômico empregado deste a Revolução Industrial vinha acarretando enorme destruição ao meio ambiente (POTT; ESTRELA 2017).

Neste sentido, a ideia de progresso, que perdurou na base da ciência moderna, sofre questionamentos, visto que, com a crise ambiental, o esgotamento dos recursos naturais e a desigualdade social, apesar do desenvolvimento tecnológico, colocou em cheque a ideia de que a ciência conseguiria resolver todos os problemas da humanidade.

A Conferência das Nações Unidas sobre o Meio Ambiente, afamada Conferência de Estocolmo, onde foram definidos diversos princípios que nortearam as decisões envolvendo as questões ambientais. (POTT; ESTRELA 2017).

Posteriormente, a Organização das Nações Unidas (ONU) criou a Comissão Mundial sobre Meio Ambiente e Desenvolvimento, formada por 40 especialistas ambientais de diferentes países. As análises feitas por essa Comissão geraram o relatório de Brundtland, que demonstrou a existência de um vínculo entre desenvolvimento econômico e proteção ambiental; foi também onde surgiu o termo "desenvolvimento sustentável", compreendido como "aquele que atende as necessidades das gerações presentes sem comprometer a possibilidade das gerações futuras satisfazerem suas próprias necessidades" (BRUNDTLAND 1987 apud OLIVEIRA, 2008, p.28).

Por conseguinte, a má utilização dos recursos naturais começou novamente a ser um motivo de preocupação, visto que passou a causar sérios problemas ambientais (CANCIO, 2017). Nesse contexto entra a importância da adoção de práticas ambientais sustentáveis. Acresce-se que esse dilema é percebido frequentemente pelas organizações, contudo na maioria das vezes não apenas por preocupação, algumas vezes decorrente de coerção por parte do Estado, através de leis e normas ou interesses particulares.

Diante disso, a proposta desta pesquisa é responder a seguinte problemática: "quais são as práticas da gestão ambiental desenvolvidas no Fórum da comarca de Juara-MT?" e "como os servidores públicos atuam em relação a essas questões em seu dia a dia de trabalho?".

Pensando nisso, o tema de pesquisa tem como objetivo geral compreender quais são as práticas da gestão ambiental desenvolvidas no Fórum da comarca de Juara-MT, e tem como objetivos específicos identificar as práticas ambientais adotadas pelo Tribunal de Justiça do Estado de Mato Grosso para o Fórum da comarca de Juara, analisar o conhecimento dos servidores em relação às 
mesmas e levantar quais são as práticas ambientais adotadas pelos servidores em seu dia a dia de trabalho.

\section{FUNDAMENTAÇÃO TEÓRICA}

\subsection{Gestão ambiental}

De acordo com o art. 225 da Constituição Federal, todos têm direito a um meio ambiente ecologicamente equilibrado, e ao uso comum e essencial para a qualidade de vida sadia, cabendo ao Poder Público e à sociedade o dever de proteger e assegurar esses direitos (BRASIL, 2017).

A gestão ambiental pública atualmente no Brasil é regida pela lei 6.938/81, cujo principal objetivo é preservar e recuperar o meio ambiente, por meio do Sistema Nacional do Meio Ambiente - Sisnama (BRASIL, 1981).

Nesse sentido, Seiffert (2009) comenta que gestão ambiental neste contexto depende exclusivamente de ações propostas pelo governo em suas políticas ambientais. Porém, também é importante saber gerir e administrar os recursos naturais, pois, conforme afirma Maximiano (2006), essas ações estão englobadas nos atos de planejar, executar, organizar e controlar recursos, na incessante busca das organizações pelo alcance de seus objetivos.

\subsection{Sustentabilidade social, ambiental e econômica}

O termo sustentabilidade ou desenvolvimento sustentável, originou-se por volta da década de 80 , quando diversos países perceberam a necessidade de descobrir formas de manter o crescimento econômico mundial que estava ocorrendo no momento, sem prejudicar a natureza (SAVITZ; WEBER, 2007).

Diferentemente do que muitos pensam, sustentabilidade não está relacionada apenas com a natureza, que segundo Elkington (2001), a sustentabilidade está diretamente associada a três áreas: social, ambiental e econômica, conhecidas como o tripé da sustentabilidade.

Em relação à sustentabilidade econômica, Sartori et al (2014) a definem como o equilíbrio de capital, para que não haja diminuição da economia. Também pode ser definida como a junção de práticas econômicas, financeiras e administrativas com o objetivo de promover o desenvolvimento econômico de uma determinada esfera sem prejudicar os recursos naturais (SEBRAE, 2017).

Já a sustentabilidade social é responsável por analisar as interações ocorrentes entre os indivíduos e o meio onde vivem (VALLANCE et al 2011, apud SARTORI et al, 2014). Deste modo, pode-se dizer que ela está diretamente relacionada à prática de atos conscientes e voluntários praticados independentemente de qual seja o ambiente, em prol de uma determinada causa. 
Por fim, no dizer de Cavalcanti et al. (1994) apud Gonçalves (2005), a sustentabilidade ambiental está relacionada à chance que um ecossistema tem de dar condições de vida para os seres nele existentes e manter ou elevar essas condições para as suas futuras gerações.

\subsection{Responsabilidade social}

De acordo com Ursini e Sekiguchi (2005), a responsabilidade social pode ser definida como as relações éticas das organizações no caminho para um desenvolvimento sustentável. É importante lembrar que quando nos referimos às organizações, está incluído nela o ser humano, como pessoa, pois de acordo com Chiavenato (2000), os indivíduos são os que comandam as organizações.

Para Fraedrich e Ferrel (2000), uma organização socialmente responsável é aquela que durante o processo de busca para atingir seus objetivos para com a sociedade, e consegue levar em consideração questões como a legalidade, economia e a filantropia.

Uma definição interessante de responsabilidade social é a formulada por Elhauge (2005) apud Junior (2013); para ele, é necessário deixar de lado a intenção de obter o lucro para dar prioridade às questões sociais. Em contrapartida, Porter e Kramer (2006) afirmam que a maioria das empresas não sabem praticar ações sociais de qualidade, exatamente porque deixam de lado a obtenção de lucro; para os autores, as empresas devem aplicar a denominada "filantropia empresarial", ou seja, praticar ações em prol da sociedade não apenas pelo ato de humanitarismo, mas visando obter algum lucro, mesmo que indiretamente.

\subsubsection{Responsabilidade social no judiciário}

O Estado deve assumir as responsabilidades sociais como qualquer outra empresa, visando basicamente dois objetivos essenciais: evitar a degradação ambiental e garantir melhores condições de trabalho para os seus servidores (DIAS, 2012). O autor diz ainda que no âmbito do setor público, o Estado iniciou sua participação nos debates sobre responsabilidade social, quando diversas organizações internacionais começaram a observar e analisar os papéis do governo, como facilitador, regulador, aliado e apoiador.

Segundo Aragão (1997) e Arantes (2007), quando se tratava de administração pública, pouco se discutia sobre o Poder Judiciário. Conforme relata Nogueira (2011), essa situação só mudou após a criação do Conselho Nacional de Justiça (CNJ), que passou a elaborar relatórios e divulgá-los, facilitando com isso o acesso às informações.

É papel do Poder Judiciário interpretar leis e aplicá-las, porém, de acordo com Lima (2014), o judiciário não deve ser apenas um aplicador de leis, mas adotar de forma efetiva em seu cotidiano ações que contribuam com a preocupação e a responsabilidade em relação às questões ambientais. 
Pensando nisso, o Tribunal de Justiça de Mato Grosso (TJMT) conta com o apoio do Núcleo de Responsabilidade Socioambiental Permanente do Judiciário, responsável pelo Plano de Logística Sustentável (PLS), aprovado em 2007, que visa a preservação do meio ambiente, e estímulo à adoção de práticas sustentáveis (T.J.M.T, 2013).

\section{MATERIAIS E MÉTODOS PARA PESQUISA}

\subsection{Abordagem da pesquisa}

Para esse estudo a abordagem da pesquisa é qualitativa, pois conforme relata Sampiere (2010), a pesquisa qualitativa baseia-se em análise e exploração de dados em conjunto com uma base teórica.

\subsection{Natureza dos objetivos}

A pesquisa possui objetivos de natureza exploratória e descritiva. Segundo Gil (2002), a pesquisa exploratória permite conhecer um determinado tema de maneira mais aprofundada e possibilita novos descobrimentos. Esse tipo de pesquisa foi escolhido, pois apesar da existência de diversos estudos em relação a práticas ambientais no judiciário, não existe estudos específicos na área realizados e divulgados com relação especificamente ao Fórum da comarca de Juara, Estado de Mato Grosso (MT). Em relação à pesquisa descritiva, de acordo com Gil (2002), ela tem como finalidade principal descrever os fatos de determinada realidade. Deste modo foi escolhida diante da necessidade de descrever detalhadamente diversos elementos primordiais para proporcionar clareza à pesquisa, além de possibilitar o emprego de técnicas para a coleta de dados, que é de fundamental importância para que este estudo possa atingir seu objetivo.

\subsection{Delineamento de pesquisa}

Para coleta de dados foram selecionados os procedimentos técnicos estudo de caso e pesquisa bibliográfica.

Esta pesquisa foi realizada por meio de um estudo de caso realizado no Fórum Dr. José Lima Rodrigues, localizado na comarca de Juara-MT. Os sujeitos de pesquisa foram todos os servidores, sem distinção em relação a cargo, que responderam ao questionário. Na data da realização da coleta nem todos os servidores estavam presentes, deste modo, 42 foram os que responderam ao questionário.

Segundo Yin (2010), o objetivo do estudo de caso é investigar fatos da atualidade de forma detalhada. Para isso, será realizada primeiramente uma pesquisa bibliográfica sobre gestão ambiental, sustentabilidade social, ambiental e econômica e responsabilidade social. Este estudo bibliográfico 
será realizado por meio de livros e artigos científicos, conforme afirma Gil (2002, p. 44): "A pesquisa bibliográfica é desenvolvida com base em material já elaborado, constituído principalmente de livros e artigos científicos". Trazendo assim conceitos e teorias de diversos autores para fundamentação em relação às práticas ambientais.

\subsection{Técnicas de coleta de dados}

Para coleta de dados foi selecionado um modelo de questionário e um roteiro de entrevista. O questionário é composto por perguntas fechadas, e de acordo com Gil (2008), os questionários são ferramentas utilizadas para se obter informações, podendo descobrir de um determinado público suas opiniões, expectativas, situações vivenciadas e etc.

A entrevista foi aplicada a gestora da organização com o intuito de levantar quais são as práticas ambientais desenvolvidas dentro da instituição. Triviños (2010) define a entrevista semiestruturada como aquela que pelos questionamentos básicos se coleta informações importantes do entrevistado e estas vão se transformando em outros novos questionamentos.

Após a aplicação dos questionários e realização da entrevista, as informações foram tabuladas no formato simples e discutidas com autores das temáticas de práticas ambientais.

\section{RESULTADOS E DISCUSSÕES}

Os dados foram coletados por meio de entrevista e questionário. Inicialmente, realizou-se uma entrevista semiestruturada com a gestora onde se buscou explorar as práticas ambientais desenvolvidas e como elas são transmitidas aos servidores, as quais são apresentadas no subtópico 4.1.

Foi aplicado também um questionário composto por 12 perguntas fechadas, dividido em duas partes. A primeira parte serviu como base para levantamento das características pessoais e profissionais dos servidores, com o intuito de traçar um perfil dos agentes sociais. Na segunda parte do questionário levantaram-se dados acerca das práticas ambientais desenvolvidas durante o seu dia a dia de trabalho. Os dados que tangem o questionário são apresentados nos subtópicos 4.2, 4.3, no tópico 5 e no subtópico 5.1 .

\subsection{Práticas ambientais adotadas}

As práticas ambientais adotadas internamente foram obtidas por meio de entrevista com a gestora da organização. Inicialmente perguntou-se sobre o descarte de resíduos: 
Entrevistadora: “Onde é feito o descarte dos resíduos gerados?

Gestora: "A coleta é feita pelo próprio caminhão da prefeitura e levado para o lixão.".

Entrevistadora: "Não tem a separação do lixo?"

Gestora: "Não. Infelizmente ainda não temos".

Observa-se pela fala da gestora que não existe o descarte correto dos resíduos, tendo em vista que a comarca onde o órgão está inserido conta apenas com um depósito de lixo que fica a céu aberto e conforme disposto no art. 47, parágrafo II da lei $\mathrm{n}^{\circ} 12.305 / 10$ que diz serem proibidas as destinações de resíduos sólidos ou rejeitos a céu aberto. (BRASIL, 2010).

Conforme dito pela gestora ainda não existe a separação do lixo, porém mesmo que não exista o processo de coleta seletiva, seria interessante analisar a possibilidade de o órgão colaborar com os catadores de materiais recicláveis da região e fazer a separação desses materiais evitando assim o seu depósito em um local inapropriado.

Outro ponto questionado foi em relação à orientação e à cobrança feita aos servidores para desenvolverem as práticas ambientais.

Entrevistadora: "O TJMT institui metas a serem cumpridas em relação ao consumo de materiais de expediente e recursos naturais?"

Gestora: "Sim. Agora eles estão com a meta de diminuir consumo de papel e consumo de copos."

Entrevistador: "Mas isso é no geral? Em todas as comarcas ou é uma meta especifica da Comarca de Juara?"

Gestora: "É no geral."

Entrevistadora: "O TJMT orienta os servidores em relação ao Plano de Logística Sustentável (PLS) e a A3P?"

Gestora: "Ele orienta via e-mail. Eles estão sempre mandando, no e-mail tem direto, destinado ao grupo dos servidores, é que ninguém presta atenção, ontem mesmo mandaram um e-mail informando que eles pediram pra gente economizar $40 \%$ o consumo de copos descartáveis, por isso que a gente colocou os copos apenas para o público externo, em contrapartida era para economizar $40 \%$ e foi economizado apenas 3\%, olha a diferença."

Nesse ponto observa-se que ainda não existe o consumo consciente por parte dos servidores. De acordo com Saraiva (2011), isso ocorre porque a implantação da Agenda Ambiental da Administração Pública (A3P), por exemplo, é voluntária, o que dificulta aos gestores fazer com que os servidores apliquem as medidas propostas.

Em outro ponto da entrevista, a gestora relata também que houve algumas reuniões para orientação: 
Entrevistador: "O TJMT promove reuniões para orientar os servidores sobre consumo consciente?"

Gestora: "Promove, mas em Cuiabá."

Entrevistador: "Vai um pouco dos servidores ou vai só você e você repassa essas orientações?"

Gestora: "Todas as vezes que a gente vai lá eles falam sobre a sustentabilidade. Quando tem algum curso ou alguma outra coisa que os servidores precisam se deslocar até lá, eles já aproveitam para falar sobre isso."

Observa-se nos dois trechos da entrevista que são promovidas orientações via e-mail e em algumas ocasiões presenciais. Entretanto, conforme relatado, esses meios não foram suficientes para que o órgão atingisse a meta de redução de copos descartáveis. Isso leva a refletir sobre o porquê desses métodos não estarem funcionando. Observa-se que tem se tentado cumprir o que está instituído na política ambiental, porém sem se refletir se os resultados estão sendo realmente alcançados.

Paralelo a isso, Lima (2014) descreve que o Poder Judiciário não deve apenas cumprir as leis, mas adotar em seu cotidiano ações que irão efetivamente contribuir com a questão ambiental. Deste modo, pode-se pensar sobre a necessidade de promover ações internas baseadas na rotina e na realidade da localidade de maneira que os servidores comecem a aplicar as práticas ambientais no seu dia a dia, tendo em vista que até o momento todas as ações são trazidas de fora.

Em seguida, foi perguntado aos servidores sobre as cobranças feitas para o cumprimento das normativas ambientais.

Entrevistadora: "As normativas instituídas pelo CNJ são obrigatórias? Se sim, existe a cobrança do TJMT para que essas normativas sejam cumpridas? "

Gestora: "Existe. A normativa existe, porem ela não é cumprida como deveria, agora é que ela está começando a ser cumprida, eles estão cobrando mais, para diminuir o custo com a energia, não utilizar mais copos descartáveis, utilizar as canequinhas ou copos de vidro, porém, não se está cumprindo direito, mas a cobrança agora está aumentando. "

Nesse trecho da entrevista a gestora revela ter consciência de que as normativas ambientais não são cumpridas da maneira que deveriam.

Para que as práticas ambientais tenham sucesso é necessário que haja engajamento por parte dos gestores e servidores, pois pelas mudanças de hábitos se desenvolve uma cultura institucional voltada para a sustentabilidade na questão ambiental. Barata et al, (2007). 
Foi perguntado também em relação à existência de incentivos para os servidores colaborarem com as práticas ambientais:

Entrevistador: O TJMT avalia o desempenho da comarca em relação as práticas ambientais? Se sim, qual o desempenho da comarca de Juara atualmente nesse quesito?

Gestora: Sim. Existe uma premiação. A Comarca de Juara já ganhou o prêmio no ano de 2016. E um selo: Ouro, prata, bronze e diamante. Nós ganhamos o bronze, por termos diminuído em $50 \%$ as despesas dentro do orçamento matricial.

Nessa fala da gestora, observa-se que a alguns anos a comarca conseguiu dar um passo em relação ao desenvolvimento sustentável atingindo uma meta importante. Apesar de não terem sido detalhados os departamentos onde houveram as reduções, é importante analisar que já se passaram quatro anos e desde então a organização não ganhou outro prêmio, pelo contrário, não conseguiu reduzir o consumo de copos descartáveis que fora solicitado, conforme relatado anteriormente pela gestora.

\subsection{Perfil dos servidores}

Como se mostra no Quadro 1, a grande maioria dos servidores entrevistados é do gênero feminino.

Quadro 1- Perfil dos servidores (gênero, idade e tempo de trabalho no órgão).

\begin{tabular}{|c|c|c|c|}
\hline & FEM & MASC & TOTAL \\
\hline \multicolumn{4}{|l|}{ GÊNERO } \\
\hline $\begin{array}{c}\text { QUANTIDADE DE } \\
\text { SERVIDORES }\end{array}$ & 28 & 14 & 42 \\
\hline \multicolumn{4}{|l|}{ IDADE } \\
\hline ATÉ 20 ANOS & 6 & 5 & \\
\hline ENTRE 21 A 30 ANOS & 7 & 5 & \\
\hline ENTRE 31 A 40 ANOS & 5 & 3 & \\
\hline ACIMA DE 41 ANOS & 10 & 1 & \\
\hline TOTAL & 28 & 14 & 42 \\
\hline \multicolumn{4}{|l|}{ TEMPO DE TRABALHO } \\
\hline MENOS DE 1 ANO & 9 & 5 & \\
\hline DE 1 A 2 ANOS & 5 & 6 & \\
\hline DE 3 A 5 ANOS & 3 & 2 & \\
\hline MAIS DE 5 ANOS & 11 & 1 & \\
\hline TOTAL & 28 & 14 & 42 \\
\hline
\end{tabular}

Fonte: pesquisa de campo, 2019. 
Ainda no Quadro 1 observou-se que o gênero feminino encontra-se na faixa etária acima dos 41 anos, divergindo do gênero, masculino em que a maior parte encontra-se entre os 21 a 30 anos.

Em relação ao tempo de atuação dos servidores, o gênero feminino, trabalha no órgão a mais de cinco anos. Por outro lado, o gênero masculino a grande maioria não ultrapassa os dois anos de trabalho na organização.

\subsection{Conhecimento dos servidores em relação à questão ambiental}

Quando questionados sobre o que entendiam por sustentabilidade, dos 42 entrevistados, $38(90 \%)$ afirmaram que a sustentabilidade está relacionada a um tripé: social, ambiental e econômico, sendo esta a alternativa que mais se aproxima do conceito de sustentabilidade, conforme definido por Elkington (2001). Outros quatro (10\%) responderam que a sustentabilidade são ações que visam evitar o desperdício e aproveitar materiais.

Deste modo, pode-se dizer que a grande maioria dos servidores possui conhecimento do significado da palavra sustentabilidade. É importante analisar também que uma pequena porcentagem escolheu uma alternativa "superficial", que não está incorreta, porém demonstra que há servidores que ainda não compreendem que a sustentabilidade engloba um cenário muito mais amplo.

Quando questionados em relação à Agenda Ambiental da Administração Pública (A3P), apenas um servidor (2\%) afirmou conhecer sobre o assunto, cincos (12\%) disseram conhecer um pouco sobre o assunto A3P; dez servidores $(24 \%)$ relataram já terem ouvido falar, mas não conhecem e 26 (62\%) responderam que desconhecem totalmente o assunto.

Se deixarmos de analisar essa questão no geral e analisarmos pelo gênero dos servidores, observa-se que apenas uma servidora (4\%) afirmou conhecer a A3P, contra um servidor (7\%) do masculino; no mesmo sentido, 18 servidoras (64\%) afirmaram desconhecer totalmente a A3P, contra 57\% dos homens. Outras três $(11 \%)$ servidoras responderam que conhecem, porém, pouco sobre o assunto, enquanto dois (14\%) servidores responderam com a mesma alternativa e ainda outras seis (21\%) responderam que já ouviram falar, mas não conhecem sobre o tema, mas não conhecem, enquanto apenas três servidores $(21 \%)$ do gênero masculino responderam utilizando a mesma alternativa. Assim sendo, evidencia-se que apesar do gênero feminino ter mais tempo de trabalho no órgão, o gênero masculino demonstrou maior conhecimento sobre a A3P.

\subsection{Práticas ambientais adotadas pelos servidores em seu cotidiano}

Os servidores também foram abordados acerca de suas ações em relação ao meio ambiente em seu dia a dia de trabalho. A primeira questão é sobre a separação do lixo que pode ser reciclado, 18 servidores (43\%) responderam que poucas vezes fazem a separação; $16(37 \%)$ disseram que nunca fazem a 
separação dos materiais, quatro $(10 \%)$ disseram que às vezes fazem e outros quatro $(10 \%)$ responderam que fazem a separação com frequência. Os resultados são compreensíveis, tendo em vista que na região onde o Fórum da Comarca de Juara-MT está instalado não existe o sistema de coleta seletiva, deste modo, os materiais serão depositados no mesmo local havendo ou não o processo de separação.

Outra questão sobre os hábitos cotidianos, indagou-se aos servidores a respeito da economia de energia elétrica, $34(81 \%)$ responderam que sempre apagam as luzes, desligam o ar condicionado e outros aparelhos ao sair do ambiente; sete $(17 \%)$ responderam que frequentemente o fazem e um $(2 \%)$ respondeu que poucas vezes, ninguém respondeu com a alternativa "nunca". Os dados levantados com essa questão mostram um número satisfatório em relação à conscientização sobre consumo consciente de energia elétrica, o que é importante ressaltar, tendo em vista que é um dos pontos discutidos na da política de sustentabilidade desenvolvida pelo TJMT.

A última questão é em relação ao desperdício de papel, 23 servidores (55\%) responderam que sempre evitam fazem a impressão de documentos irrelevantes, $15(36 \%)$ responderam que evitam com frequência, três $(7 \%)$ responderam que poucas vezes evitam e um $(2 \%)$ respondeu que nunca evita. Observa-se que os servidores controlam o desperdício de papel, o que é um ponto positivo e extremamente importante para a organização, tendo em vista ser um dos principais resíduos gerados, conforme afirmou anteriormente a gestora.

\section{CONSIDERAÇÕES FINAIS}

A elaboração do presente estudo teve como objetivo compreender quais são as práticas da gestão ambiental adotadas pelo Tribunal de Justiça do Estado de Mato Grosso para o Fórum da comarca de Juara/MT, e como os servidores atuam no contexto ambiental no seu dia a dia de trabalho. Em vista disso, observou-se que apesar de a maioria dos servidores atuar a pouco tempo no órgão, possui certo conhecimento quando o assunto são as questões ambientais no geral.

Entretanto, o que se percebe é que o trabalho sempre fez parte da vida do indivíduo, sendo capaz de satisfazer suas necessidades econômicas, sociais e o pouco conhecimento formal em relação ao descarte dos resíduos produzidos nos seus ambientes de trabalho, fazem com que os servidores não coloquem em prática a sua relação ao meio ambiente. Pode-se afirmar que não há uma educação ambiental popular no sentido da prática da coleta seletiva, o que resultaria no reaproveitamento de materiais recicláveis, na reutilização e redução no consumo, por isso é reprodução automática dos servidores no seu espaço de trabalho. 
É imprescindível a necessidade da realização de atos que busquem trazer aos servidores da Comarca de Juara/MT, maiores informações sobre as políticas ambientais desenvolvidas pelo TJMT e dados sobre seu desempenho ambiental ao longo dos últimos anos, para que eles se atualizem, conheçam e busquem colaborar mais com os princípios sustentáveis da instituição onde atuam.

Esta pesquisa também mostrou que o fato de os resíduos estarem sendo depositados em um local inadequado e não utilizarem de nenhum mecanismo para minimizar o problema comprova que a organização apesar de todos os esforços teóricos com normativas e políticas sustentáveis, na prática ainda há muito que ser trabalhado para minimizar - os impactos de degradação do meio ambiente.

Por conseguinte, o principal fator para o órgão públicos em não atingirem seus objetivos ambientais é porque se necessita de maior participação dos servidores nos programas ofertados internamente, uma vez que, segundo Chiavenato (2000), que os indivíduos são atores importantes no comando de uma organização. Porquanto, mesmo que haja recursos financeiros disponíveis, mas senão houver uma sensibilização e/ou formação aos servidores os esforços para minimizar os impactos ambientais, como a degradação da paisagem natural, contaminação do solo, dos rios serão ineficientes. Vale salientar que trabalhos dessa natureza são imprescindíveis para maior conscientização sobre algumas falhas que podem fazer toda diferença no processo de busca por uma organização sustentável, tendo em vista que não basta teoria, é preciso construir uma cultura forte em que os servidores públicos as coloquem em prática. A preocupação de como é realizado o processo de descarte dos resíduos, tratamento e deposição final nos lixões afeta a vida de toda coletividade, tornase uma questão pública de todos.

\section{REFERÊNCIAS}

ARAGÃO, C.V. Fatores agilizadores e restritivos à atuação da Justiça do Trabalho: um estudo exploratório. Revista de Administração Pública, jul/ago, 1997. Disponível em: <http:/bibliotecadigital.fgv.br/ojs/index.php/rap/article/view/7886>. Acesso em: 13 de outubro de 2019.

ARANTES, R. Judiciário: entre a Justiça e a Política. In: AVELAR, L; Cintra, A.O. (Org). Sistema político brasileiro: uma introdução. 2ed. São Paulo: Unesp, 2007.

BARATA, M.M.L; KLIGERMAN, D. C; MINAYO, G.C. A gestão ambiental no setor público: uma questão de relevância social e econômica. Ciênc. Saúde coletiva. Rio de Janeiro, 2007.

BRASIL. Constituição 1988. Constituição da República federativa do Brasil. Brasília, DF: Presidência da República, 2017. Disponível em: <https://www.senado.leg.br/ 
atividade/const/con1988/con1988_06.06.2017/art_225_.asp >. Acesso em: 07 de outubro de 2018.

BRASIL. Política Nacional do Meio Ambiente, 1981. Disponível em: http:/ / planalto. gov.br/ccivil_03/LEIS/L6938.htm. Acesso em: 07 de setembro de 2018.

BRASIL. Política Nacional de Resíduos sólidos - Lei 12/305/10. Disponível em: http:/ / www.planalto.gov.br/ccivil_03/_ato2007-2010/2010/lei/12305.htm.

CANCIO, A. Problemas ambientais que afetam o planeta: água. Revista Jus Navigandi, 2017. Disponível em: https:/ /jus-com-br.cdn.ampproject.org/v/s/jus.com. br/amp/artigos /62702/1?amp_js_v=a2\&amp_gsa=1\&usqp=mq331AQCKAE $\%$ 3D\#aoh=15752558507117\&referrer=https $\% 3 \mathrm{~A} \% 2 \mathrm{~F} \% 2 \mathrm{Fwww}$.google.com\&amp_tf=Fonte $\% 3 \mathrm{~A} \% 20 \% 251 \% 24$ s\&ampshare=https $\% 3 \mathrm{~A} \% 2 \mathrm{~F} \% 2 \mathrm{Fjus.com} . \mathrm{br} \% 2 \mathrm{Fartigos} \%-$ 2F62702\%2Fproblemas-ambientais-que-afetam-o-planeta-agua. Acesso em: 18 de jun de 2019.

CHIAVENATO, Idalberto. Como transformar Rh: de um centro de Custo em um centro de Lucro. $2^{\mathrm{a}}$ ed. São Paulo: Maroon Books, 2000.

DIAS, R. Responsabilidade Social: Fundamentos e Gestão. São Paulo: ATLAS, 2012.

ELKINGTON, John. Canibais de garfo e faca. São Paulo: Makron Books, 2001.

FRAEDRICH, J.; FERREL L. Ética Empresarial: Dilemas, Tomadas de Decisões e Casos. $4^{\mathrm{a}}$ ed. Rio de Janeiro: Reichmann e Affonso Editores, 2000.

GIL, A.C. Métodos e técnicas de pesquisa social. 6 ed. São Paulo: Atlas, 2008.

Como elaborar projetos de pesquisa. 4. Ed. São Paulo: Atlas, 2002.

GONÇALVES, D.B. Desenvolvimento sustentável: o desafio da presente geração. Revista Espaço acadêmico, ano V, n. 51, ago 2005.

JUNIOR, A.C. A (ir) relevância jurídica da responsabilidade social das empresas. Revista Jus Navigandi. Teresina. 29 ago. 2013. Disponível em: https:/ /jus.com.br/ artigos/25175. Acesso em 04 outubro 2018.

LIMA, L.P.A. O papel do Poder Judiciário no meio ambiente. Revista Jus Navigandi, Teresina, 15 agos. 2014. Disponível em: <https://jus.com.br/artigos/31029>. Acesso em: 7 out. 2018.

MAXIMIANO, A.C.A. Teoria Geral da Administração: da revolução urbana à revolução digital. 6 Ed. São Paulo: Atlas, 2006.

NOGUEIRA, J.M.M.A. A ausência do poder judiciário enquanto objeto de estudo da administração pública brasileira. Revista Díke, 2011. 
OLIVEIRA, J.A.P. Empresas na Sociedade: sustentabilidade e responsabilidade social. Rio de janeiro: Elsevier, 2008.

PORTER, M.; KRAMER, M. Estratégia e Sociedade. Harvard Business Review, p.134166, 2006.

POTT, C.M.; ESTRELA, C. C. Histórico Ambiental: desastres ambientais e o despertar de um novo pensamento. Estud. Av., São Paulo, v.31, n. 89, p. 271283, Apr. 2017. Disponível em:http:/ /www.scielo.br/scielo.php?script=sci_ isoref\&pid=s010340142017000100271\&lng=en\&tlng=pt. Acesso em: 27 de ago de 2019.

SAMPIERE, R.H. et al. Metodologia da Pesquisa. 5.ed. São Paulo: Penso, 2010.

SARAIVA, V.M; RÊGO, G.P. Agenda Ambiental na Administração Pública. Rio Grande do Norte, 2011.

SARTORI, S; LATRÔNICO, F; CAMPOS, LUCILA, M.S. Sustentabilidade e Desenvolvimento Sustentável: Uma taxonomia no campo da literatura. São Paulo: 2014

SAVITZ, Andrew W.; WEBER, Karl. A empresa sustentável: o verdadeiro sucesso é o lucro com responsabilidade social e ambiental. Rio de Janeiro: Campus; 2007.

SEBRAE. Sustentabilidade econômica: como sua empresa pode ter mais lucratividade com a sustentabilidade / Cuiabá: Collor, 2017.

SEIFFERT, M. E. B. Gestão ambiental: instrumentos, esferas de ação e educação ambiental. São Paulo: Atlas, 2009.

TJMT, Núcleo de Responsabilidade Socioambiental; 2013. Disponível em: <http:/ / www.tjmt.jus.br/Institucional/C/41455/\#.W7qxwnPmM0O>, acesso em: 08.10.2018.

TRIVIÑOS, A.N.S. Introdução à pesquisa e ciências sociais: a pesquisa qualitativa em educação. 1.ed. São Paulo: Atlas, 2010.

URSINI, T.R; SEKIGUCHI, C. Desenvolvimento Sustentável e Responsabilidade Social: rumo à terceira geração de normas ISO. São Paulo: UNIEMP, 2005.

YIN, R.K. Estudo de caso: planejamento e métodos. 4. Ed. Porto Alegre: Brookman, 2010. 